\title{
Kültürün Yeniden Üretim Aracı Olarak Sosyal Medya'nın Gençliğe Etkisi
}

\author{
$\underline{\text { Serkan Yorgancilar }}^{*}$ \\ *Öğr. Gör., Gazi Üniversitesi, Adalet Meslek Yüksek Okulu, Ankara/Türkiye \\ E-Posta: serkanyorgancilar@gmail.com ORCID: $\underline{\text { 0000-0002-8438-2012 }}$
}

\section{Öz}

Gençliğin gündelik yaşam pratiklerini ve bunu oluşturan kültürel değerleri anlamak için sosyal bilimlerde birbirinden farklı sınıflandırmalar yapılmıştır. Bu sinıflandırmalar gençliğin tüketim alışkanlıklarından, psiko-sosyal biliş düzeylerine kadar birçok farklı alanda kimi zaman birbirini destekleyen kimi zaman ise birbirinin tamamen zıt sinıflandırmalar şeklinde tezahür etmektedir. İslam Dünyası, Müslüman Gençlik ve Türk Gençliği bağlamında düşünüldüğ̈̈̈nde gençliğin teknolojinin ve bilimin tüketicisi olmaktan henüz kurtulmamış olduğunu görmekteyiz. Gençlik, Batı'da olduğu gibi modern teknolojik gelişimleri son derece hızl bir biçimde takip etmekte ve tüketim noktasinda rekabetçi bir görünüm arz etmektedir. Oysa aynı rekabetçi tutumu bilimi ve teknolojiyi üretmek noktasında yeterince gösterememektedir. Teknolojik gelişmeler gençliğin dönüşümünde çok büyük bir anahtar rol oynamaktadır. Teknolojik gelişmeler içerisinde ulaşımı en kolay ve ucuz olan alanlardan birisi şimdilik sosyal medya olarak görülmektedir. Bu kapsamda gençliğin yaşamında sosyal medyanın oynadı̆̆ı rolü bilmek, gençliğin yönelimlerini tahmin etmek açısından önemlidir. Yapılan bir çok araştırma göstermektedir ki Türk gençliği sosyal medyayı son derece aktif bir biçimde kullanmaktadır. Akıllı telefonlardan sosyal medya hesaplarına anlık erişim sağlayabilen gençlik siyasal katılımdan, eğlenceye, kültür-sanattan boş vakit geçirmeye kadar farklı amaçlar için sosyal medyayı kullanmaktadır. Gençlerin sosyal medya kullanma gerekçeleri birbirinden çok farklı amaçlar taşıyor olsa da sosyal medyanın kullanıclarını değiştirici/dönüştürücü bir etkisi var. Bu etki zamanla daha da artacak ve farklilaşacaktır. Bu kapsamda toplum tarafindan çeşitli biçimlerde üretilen kültürün sosyal medya aracılığıyla nasıl yeniden üretildiğini ve bu üretim sonucunda gençliğin kültürel davranışlarının nasıl değiştiği üzerinde durulacaktır.

Anahtar Kelimeler: Kültür, gençlik, sosyal medya, değişim, teknoloji

OPUS (c) Uluslararası Toplum Araştırmaları Dergisi-International Journal of Society Researches ISSN:2528-9527 E-ISSN : 2528-9535

http://opusjournal.net 


\title{
The Effect of Social Media as a Means of Re-production of Culture on Young People
}

\begin{abstract}
To understand the daily life practices of young people and the cultural values that make up these practices, classifications that were different from each other have been made in social sciences. These classifications come before us in many different areas that range from consumption habits of young people to their psychosocial cognition levels, sometimes supporting each other and sometimes in the form of classifications that opposing each other completely. When the issue is considered in the context of the Islamic world, Muslim youth and Turkish youth, we can see that young people have not recovered from being consumers of technology and science yet. Young people, as it is the case in the West, follows technological developments in an extremely fast manner and show a competitive appearance in terms of consumption. However, they cannot show the same competitive attitude in producing science and technology at an adequate level. Technological developments play a key role in the transformation of young people. One of the easiest and cheapest areas for access in technological developments seems to be the social media. In this context, it is important to know the role of the social media in the lives of young people and to estimate the orientation of them. Many studies show that Turkish young people use the social media in an extremely active way. Young people, who can have instant access to social media accounts through their smart phones, use social media for different purposes ranging from political participation to entertainment, from culture-art, to and to leisure activities. Although the reasons of young people for using social media have very different aims, it has a modifying/transformative effect. This effect will increase and differentiate in time. In this respect, the focus will be on how culture produced by society in various ways is re-produced through social media, and how cultural behaviors of young people change as a result of this production in the present study.
\end{abstract}

Keywords: Culture, young people, social media, change, technology

OPUS (c) Uluslararası Toplum Araştırmaları Dergisi-International Journal of Society Researches ISSN:2528-9527 E-ISSN : 2528-9535

http://opusjournal.net 


\section{Giriş}

Bazı kavramlar insan ve toplum yaşamında son derece önemli yer işgal ederler. Sosyal bilimlerde herhangi bir olguyu tanımlamada kullanılan ilk yöntem onun sınırlandırılmasıdır. Herşeyi içerecek büyüklükte bir kavram sorunlu olduğu gibi sosyal bilimlerin metoduyla da uyumluluk arz etmez. İnsan ve toplum yaşamında neredeyse sınırları tam olarak çizilemeyen, neyi kapsadığı ve neyi dışarda bıraktığı konusunda kafa karışıklığ tamamlanmamış olan bu kavramlardan en önemlisi kültürdür. Kültür sosyolojisinin önemli teorisyenlerinden kabul edilen Pierre Bourdieu, Alfred Weber, Lipp gibi isimlerin külür kavramını tanımlama çabaları buna örnek olarak gösterilebilir. Kültür kavramının 150 yıldır kullanıldığını varsayılmakla birlikte bu kavramı ilk tanımlayan düşünür ise Tylor'dur (Aydın, 2018, s.46).

Williams İngiliz dilinin en karmaşık iki ya da üç kelimesinden birinin kültür olduğunu söyler (Williams, 1996, s.167). İngilizcede ki ilk kullanımlarında kültür, hayvan ve ekin yetiştirme ve dinsel tapınma ile ilişkiliydi ve kült sözcügünden türetilmişti. On altıncı yüzyıldan on dokuzuncu yüzyıla kadar ise kültür kavramı daha farklı bir kullanıma kavuşmaya başlamıştır. İnsanların bireysel akıllarına ve kişisel görüşlerine uyarlanmıştır. İlerleyen dönemlerde kültür, uygarlık sözcügüüle de birleşmiş ve toplumların gelişmişliklerini ifade eden bir hal almıştır (Smith-Riley, 2016, s.19). Williams kültürü üç şekilde tasnif eder. Birey, grup ya da toplumun entelektüel, akademik ve kültürel gelişmişlik düzeyi birinci kültür tanımını ifade eder. İkinci kültür tanımına göre ise kültür yalnızca güzel sanatlar faaliyetlerini içerir. Son tanıma göre ise bir insan veya toplumun tüm yaşam faaliyetlerini kapsar. Her ne kadar geçmişte kültür tanımı için daha sıklıkla birinci ve ikinci tanımlar kullanılırken günümüz sosyal bilimlerinde kültür son derece kapsayıcı bir tanım olan üçüncü tanımın kullanım içeriğine sahiptir (Williams, 1996, s.165).

Ziya Gökalp kültür kavramını hars kavramı ile tanımlamıştır. Ona göre kültür yereldir, ulusal özellikler taşır, bir milletin kültürü sadece kendine özgüdür, bu bakımdan kültür başka milletlere aktarılamaz. Dil, din, edebiyat, güzel sanatlar, ekonomi, gelenek ve göreneklerin tamamı kültürü oluşturan ana unsurlardır. Kültür bu şekilde tanımlandığında medeniyetten açık biçimde ayrışmış olur. Çünkü medeniyet millet 
üstüdür, insan edimlerinin kültürler arası etkileşimlerini de içerir. Zaman ve şartlara göre değişebildiği gibi sade tek bir millete ait değildir. İnsanlığın ortak ürünüdür (Gökalp, 2014, s.46). Bir imparatorluk düşünürü olarak Batı' da ortaya çıkan fikir hareketlerini yakından izleyen ve Durkheim sosyolojisi ile bağlantılı olan Gökalp (Türkdoğan, 2015, s.15)'in kültür üzerinde yapmış olduğu tanımlama ardından gelen Türk sosyal bilimciler için ufuk açıcı olmuştur.

Doğu Fransa' da Yahudi geleneklerine bağlı bir topluluk içerisinde bir hahamın oğlu olarak doğan ve okul hayatı boyunca İbranice ve kutsal metinler okuyan Durkheim'e göre toplum, bireylerin ve eylemlerim olduğu kadar fikir ve inanış birliğidir de. Toplumu böylesine geniş bir yelpazeden tanımlayan Durkheim, kültürü de aynı biçimde tanımlar. Aslında o, kültürü doğrudan tanımlamak yerine kendi metodolojisine uygun olarak kültürün işlevleri üzerinde durur. Kültürün en büyük işlevini de toplumsal uzlaşmayı ve toplumsal bütünlügü sağlaması olarak ortaya koyar. Durkheim'e göre kültür, bireylerin seçimlerinden çok ihtiyaçlar ve toplumsal yapının oluşturduğu zorunluluklardan doğar (Alver, 2010, s.200). Elbette bireyler kültürün hem etkisi altında kalanlar hem de onu yeniden üretenlerdir. Ancak bireylerin seçimleri, duyguları ve düşünceleri kültürü tek başına inşa etmeye yetmez. Bireyler ve toplumsal zorunluluklar arasında belirli bir bağ vardır ve bu ilişkiler bu bağ ekseninde yürür.

Toplumu bireylerin kesintisiz etkileşimlerinin ürünü olarak gören George Simmel, insanların toplum oluşturabilmek amacıyla nasıl bir araya geldiklerini, toplumsal varlıklarını devam ettirebilmek amacıyla oluşturmuş oldukları grupların nasıl şekillendiğini ve birbirleri ile sürekli olarak devam ettirdikleri etkileşimin nasıl olduğunu araştırmıştır. Simmel, kültür kavramının temellerinin toplumsal yaşamın derinliklerinde aranması gerekliliğine inanır ve soyut toplum modelleri yerine somut etkileşim modellerinden yanadır. Simmel kültürü, Nesnel kültür ve öznel kültür olarak iki kategoride inceler. Sanat, bilim, felsefe gibi insanların ortak üretimleri nesnel kültüre, nesnel kültürün ürünlerini yaratma, özümseme gibi durumlarıda öznel kültüre ilişkilendirir. Ona göre kültür insanın kusursuzlaştırılmasıdır (Simmel, 2009, s.332).

Kültür giydiklerimiz, duyduklarımı, izlediklerimiz ve yediklerimiz, kendimizi diğerlerine göre nasıl görüp yorumladığımız, yemek yapma ve 
yemek yeme adetlerimiz, alış veriş yapmak gibi gündelik faaliyetlerimiz yani hayatımızın temel malzemesi olan, olağan bilgi ve kavrayışlarımızın tuğla ve çimentosudur (Turner, 2016, s.10).

Kroeber ve Kluckhon, kendi dönemlerine kadar yapılmış olan sayısız kültür tanımında kullanılmış olan aynı odak noktalarından hareketle bir sınıflandırma yapmışlar ve kültürü yedi şekilde sınıflandırmışlardır. Bunlar, tanımlayıc1, tarihsel, normatif, psikolojik, yapısal, genetik ve tamamlanmamış tanımlardır. Bunlardan birinsici betimsel tanımlar olup, betimsel tanımlar toplumsal yaşamı meydana getiren bütün olayların bir bileşkesi olarak kültürü tanımlarken, ikinci yaklaşım olan kültürü tarihsel açıdan tanımlayan yaklaşımlar ise onu toplumsal miras ve kültürel aktarım açısından tanımlamışlardır. Toplumların maddi kuralları, yaşayış biçimleri, davranış şekilleri bakımından yapılan tanımlar üçüncü tanımlar olup normatif tanımlar olarak adlandırılmıştır. Dördüncü olarak kültür tanımı ise psikolojik yaklaşım olarak nitelendirilebilecek olan merkezine bireyleri, bireylerin davranış biçimlerini, bireysel tutumlarını, problem çözme yeteneklerini ele alan yaklaşımdır. Kültürü soyut bir yapı olarak ele alan ve toplumsal organizasyonlar olarak ona yaklaşan tanım ise yapısal tanım olarak sınıflandırılmıştır. Kültürün son iki tanımlama biçiminden birisi genetik tanımlar iken yedincisi ise tamamlanmamış tanımlardır (Kroeber ve Kluckhon, 1952, ss.41-71).

Kültürü tanımlamanın ve sınırlandırmanın zorluğu neredeyse bütün sosyal bilimciler tarafından ortaklaşa kabul edilen bir durum haline gelmiştir. Hatta bazı sosyal bilimciler bir kavramın bu kadar sınırsız tanımının olmasının, bir kavram üzerinde bu kadar çok sosyal bilimcinin ittifak edememiş olmasının da ayrıca ciddi bir sorun olduğuna inanmaktadır. Kültür kavramının içeriğinin sınırsız olması kavramı tanımlamada zorluklara neden olmaktadır. Bozkurt Güvenç'te kültür kavramının içeriğinin belirsizliğine işaret ettikten sonra, bu kavramın daha rahat bir mecrada anlaşılabilmesi için dörtlü bir kültür tasnifi yapmıştır. Batı ve İslam kültürü, Çin ve Hint Kültürü gibi aslında medeniyet anlamında kullanılabilen, belirli toplumsal inanç gruplarının veya milletlerin ortak yaşam biçimlerinin ürünleri olarak kültürü birinci başlıkta ele almıştır. Böylesine bir kültür tanımı bilim alanında ki kültür olarak ta anlaşılabilir. Meslek ve teknik eğitimi, tıp, hukuk, din, örgün ve yaygın eğitimi ifade eden beşeri alandaki kültür ise ikinci sınıftır. Üçüncü olarak ise gotik, 
barok, Rönesans ve modern sanat ve müzik gibi güzel sanatlara ve estetik alana işaret eden çıtılardır. Dördüncü olarak ise tarım, hayvancılık ve endüstri kültürü gibi maddi ve biyolojik alandaki kültürdür (Güvenç, 1996, s.97). Dolayısıyla bütün bu sınıflandırmadan ortak bir kültür tanımı çıkmasa da kültüre ait belirleyici özellikler ortaya konulabilir. Kültürün nesilden nesile aktarılabildiği, değişebildiği, farklı toplumlarda farklı biçimlerde var olabileceği, insanların bir takım sosyal sorunlarına cevap verebileceği gibi sonuçlara da ulaşılabilir.

Sosyal bilimcilerden bir kısmı kültürü toplum tarafından üretilen bir şey olarak görürken bir kısmı da toplumu yönlendiren özerk bir güç olarak görmektedir. TDK'ya "göre kültür tarihsel, toplumsal gelişme süreci içinde yaratılan bütün maddi ve manevi değerler ile bunları yaratmada, sonraki nesillere iletmede kullanılan, insanın doğal ve toplumsal çevresine egemenliğinin ölçüsünü gösteren araçların bütünü, hars, ekinidir" (TDK, 2018). İnsanların ve grupların davranışları, inançları ve düşünceleri (Macmillian, 2002, s.338) ile insan toplumlarında ki biyolojik olmayan toplumsal araçlarla aktarılıp iletilen her şey de (Marshall, 1999, s.442) kültür olarak isimlendirilir.

Aydın, kültürün temel kavramları arasında dil, gelenek, kimlik, kültürcülük, kültürleşme, sembolizm ve zihniyeti gösterir (Aydın, 2018, s.41). Bu kavramlar arasında örtülü/örtüsüz geçişkenlikler mevcuttur. Örneğin kimlik inşa etmek için hem sembolizm kullanılır hem de zihniyet. Her ikisini ortaya koyabilmek içinde dil kullanılır. Gerek sembolizm gerekse kimlik bir dil üzerinden inşa edilir. Sınırları, kapsamı, içeriği dille belirlenir. Kültür toplum tarafından üretilen ve dolaşıma sokulan bir şeydir. O halde toplum nedir. Durkheim toplumu ahlaki bir güç, Levi Strauss ise entelektüel bir güç olarak görür. Toplum ister ahlaki bir güç olarak tanımlansın isterse entelektüel bir güç olarak tanımlansın kültür, onda vardır, onunla vardır, o varsa vardır.

Kültür hakkında en özlü tanımı yapanlardan birisi de Eliot'tur. Tylor'ın 1871 gibi erken bir dönemde yaptığı ve ilk kültür tanımı olarak gösterilen insana ait herşeyi kapsayan kültür tanımını daha özlü bir biçimde ifade ederek "toplumu, toplum yapan şey'dir" şeklinde tanımlamıştır. Kültürü bütün bir hayat tarzı olarak ele alan bu bakış açısı Weber' in kültürü değerler, düşünceler, inançlar ve dünya görüşleri olarak ele alan yaklaşımına da uygundur (Eliot, 1987, s.11). 


\section{Sosyal Medya'nın Hesaplanamaz Yükselişi}

TÜİK verilerine göre ülkemizde bilgisayar ve internet kullanımı giderek yaygınlık kazanmaktadır. Bilgisayar ve internet kullanımı birlikte ele alındığında 2017 yılında 16-74 yaş grubunda sırasiyla \%56,6 ve \%66,8 olmuştur. Bu oranlar 2016 yılında sirasıyla \%54,9 ve \%61,2 olarak gerçekleşmişti. Bilgisayar ve İnternet kullanım oranları 16-74 yaş grubundaki erkeklerde $\% 65,7$ ve $\% 75,1$ iken, kadınlarda $\% 47,7$ ve $\% 58,7^{\prime}$ dir. Ülkemizde erkekler kadınlara göre daha fazla bilgisayar ve internete erişim sağlamaktadır. Teknolojiye ulaşımın kolaylaşması ve ucuzlaşması sayesinde özellikle internet kullanımında gözle görülür artış yaşanmaktadır. Gene TÜİK verilerine göre Türkiye' de insanlar evlerinden \%80.7 gibi son derece yüksek bir oranda internet erişimine ulaşım sağlayabilmektedir. (TÜİK, 2018)

British Council tarafından 2017 yılında 12 şehirde, 18-30 yaş arası 2524 genç arasında sosyal medya kullanımı ve diğer konuları da kapsayan geniş bir çalışma yapılmıştır. Ankete katılan gençlerin \%97'si günlük düzenli olarak WhatsApp ve diğer sosyal medya uygulamaların kullandıklarını ifade etmiştirler. Sosyal medya üzerine yapılan nicel çalışmalar kısa bir müddet içerisinde güncelliğini kaybetmektedir çünkü insanlar her geçen gün sosyal medyayı çok daha aktif ve farklılaşan biçimlerde kullanmaktadır. Örneğin günümüz verileriyle geçmiş verilerini karşılaştırdığımızda Temmuz 2007' de İngiltere'de yapılmış bir çalışmada gençlerin sosyal ağ kullanma sıklığı haftada sadece bir kez ölçüldügünü (Livingstone, 2016, s. 91) düşünürsek sayısal verilerin ne kadar hızlı ve değişken olduğunu görmekteyiz. British Council'ün Türkiye üzerinden yaptığı çalışmada sadece Türk gençleri sosyal medyayı günlük iki saatin üzerinde kullanmaktadır, elbette şimdilik (British Council, 2017, s.16).

Araştırmalara göre, sosyal medya mecralarının farklı kullanımları da mevcuttur. Sosyal medya mecralarının farklı kullanımları da hem üretici firmaların kullanıcı dostu ara yüzleri sayesinde hem de gençliğin değişen beklenti ve taleplerini doğru karşılayabilmeleri sayesinde değişim göstermektedir. Son veriler göre İnstagram gençlerin yüze 29'u tarafından en çok tercih edilen sosyal medya mecrası, onu izleyen yüze $27^{\prime}$ lik oranla WhatsApp, ardından ise yüze 26 ile Facebook'tur. Gençlerin yüze 67'si sosyal medyanın dünyaya açılan bir pencere ve güncel gelişmelere dair 
farkındalığı arttıran bir araç olarak görmektedir. Bununla birlikte gençlerin yüze 46'sı sosyal medyanın kutuplaştırıcı bir etkisi olduğunu da düşünüyor (British Council, 2017, s.20).

Teknolojik alt yapının ve gelişmiş yazılım sistemleri sayesinde üretilen güçlü görsellerinde etkisiyle geleneksel medya araçları olarak kabul edilen radyo, televizyon ve gazetenin yerini, CD-romlar, web siteleri, bloglar, e-postalar, elektronik kiosklar, interaktif televizyonlar, mobil medya cihazları, akıllı iletişim teknolojileri olarak sayılabilecek yeni nesil medya araçları almaktadır. Facebook, Tweeter, İnstagram, Youtube gibi paylaşım siteleri de yeni nesil medya araçları içerisinde en popüler olanlarıdır. Radyo, televizyon ve gazete gibi geleneksel medya araçları 20. yüzyılın başından beri bireyleri ve toplumsal olayları yönlendirici bir etki yaratmıştı. Gelinen süreçte geleneksel medya araçlarının etkisinin yok olduğu söylenemez ancak yeni nesil medya iletişim araçlarının daha yaygınlaştı̆̆ 1 söylenebilir. Ajans Press'in yaptığı bir araştırmaya göre günde 330 dakikayla dünyada en çok televizyon izleyen ülke Türkiye'dir (Milliyet. 03.04.2017). Televizyon izleme gerekçeleri insanlar arasında farklılıklar gösterse de ana haber bültenleri, spor programları, popüler yarışma programları ve diziler insanların en çok tercih ettikleri programların başında gelmektedir. British Council araştırmasına göre ise insanlar televizyon izlemeyi tek başına bir aktivite olarak görmemekte, özellikle aile içerisinde arka plan aktivitesi olarak televizyonun açık olduğunu belirtilmektedirler. Dolayısıyla geleneksel medya araçlarının etkisi günden güne azalma eğilimi gösterirken henüz etkinliğinin tam olarak ortadan kalktığı söylenemez.

Yeni nesil medya iletişim araçlarının kullanım sıklığının artmasında ve geleneksel medya araçlarına göre daha fazla tercih edilebilirliğinin olmasında çok farklı nedenler bulunmaktadır. Gençler, sosyal medyayı daha geniş bir dünyayı fark etmelerine yardımcı olarak görmektedirler. Ayrıca sosyal medyada kendilerini daha kolay ifade edebildiklerine inanmakta ve sosyal medya sayesinde toplumun daha farklı ve daha geniş kitleleriyle iletişim kurabildiklerine inanmaktadırlar (Hinton ve Hjort, 2013'den akt: Karataş-Binark, 2016). Dolayısıyla sosyal medyada gençlik katılımcı kültüre sahip olması ve içerik üretebilmesi gibi nedenlerden dolayı kendini bu mecrada daha rahat hissetmektedir. 
Sosyal medya kullanıcılarının büyük bir kısmı içerik üretmektedir. Sosyal medya kanallarında aktif içerik üreticiler olduğu gibi pasif üreticilerde bulunmaktadır. İçerik üretiminde bulunan kullanıcıların aktif üretici mi yoksa pasif üretici mi olduklarıla ilgili bilimsel bir ölçüt bulunmamaktadır. Kullanıcılar çoğu zaman gönüllü ve istekli olarak ürettikleri içeriklerle bilerek veya bilmeyerek profilleri ve davranışlarıyla üst-veri toplayıcılarına da hizmet etmiş olurlar. Bununla birlikte sosyal medya kullanıcıları yaş, cinsiyet, e-mail, isim, adres ve kimi zaman ise kredi kart bilgilerini de sisteme yükleyerek bilgi toplayıcılarının işini kolaylaştırırlar. Aslında kullanıcıların sisteme gönüllü veri girişinde bulunmalarında ki asıl amaç katılımcı kültürel bir davranıştır. Sisteme gönüllü veri girişinde bulunmak sıradan bireylerin tüketicilikten medya içeriklerinin yaratıcıları ve belirleyicileri konumuna yükselmiş olmalarıyla doğrudan alakalıdır (Dijk, 2016, s.161).

\section{Sosyal Medya ve Kültür}

Kitle iletişim araçları olarak nitelendirebileceğimiz iletişim kaynakları teknolojik gelişimlerden en fazla etkilenen alan olmuştur. Teknolojik gelişimin en hızlı olduğu, sürekli değişim yaşanan bir alan olan kitle iletişim araçları en etkin olarak gazetelerin matbaalarda basılıp çoğaltılmasıyla yayılmaya başlamıştır. Gazetelerin uzun süren hâkimiyetine 20. yüzyılın başlarında radyolar eşlik etmeye başlamıştır. 1950'lerden sonra ise televizyonların dünyada hızla yayılmaya başladığını görmekteyiz. Siyah beyaz televizyon teknolojisinden sonra renkli televizyonlar ilk kullanılmaya başladığı dönemlerde insanların kültür dünyalarında ciddi etkiler yaratmaya başlamıştı. Radyo ve gazetenin birkaç adım ötesine geçen televizyon teknolojisi toplumların kültürel dünyalarında daha hızlı ve gözle görülür etkiler yaratmıştır. Televizyonlardan bir adım sonrası ise bilgisayar teknolojilerinin küçülerek sıradan insanlara hitap edebilecek noktalara gelmesi ve fiyatlarının da ucuzlayarak ulaşılabilir duruma gelmesiyle yepyeni bir hal almıştır. Televizyon ve bilgisayar yüzyılımızın en büyük kültür üretim araçları haline zamanla gelmiştir. Özellikle televizyonun kültür üretim aracı haline gelmesiyle tartışmaları üzerine çekmiş bir kısım insanlar televizyonun zararlı olduğunu iddia etmişken bir kısım insan da televizyonun son derece faydalı bir araç olduğunu iddia 
etmiştir. Günümüzden bakıldığında televizyon hakkında yürütülmüş olan bu tartışmaların son derece anormal şeyler olduğu hissine kapılınabilinir. Ancak dönemin şartları düşünüldügünde bu tartışmalar, bugün sosyal medya üzerinde yürüttüğümüz tartışmalarla eş-değerdir. Günümüzde de sosyal medyanın, internetin ve de bazı paylaşım sitelerinin bir takım zararları olup olmadığı tartışılmaktadır. Bu tartışmalar günümüz için son derece hayati önem taşısa da belki de gelecekte son derece boş ve anlamsız tartışmalar olarak görülecektir. Hızlı teknolojik ilerlemeler, sosyal medya olgusunu aşacak, çok daha farklı iletişim modelleri inşa edebilecektir. Bunu şimdiden tahmin etme imkanına sahip bile değiliz. Belki son yirmi yılda teknolojide yapılan muazzam devrimler sayesinde hiçbir şeye olumsuz yaklaşamamaktayız ve gelecekte çok fazla şeyin akıllı modellemelerle insansız bir şekilde yapılabileceğini düşünmekteyiz.

Giddens iletişimi bir grup ya da kişinin başkası ile sözlü veya başka bir araç vasıtasıyla kurduğu ilişki olarak tanımlar (Giddens, 2000, s.401). İletişimin en başat sonucu toplumsallaşmadır. Bireyler, iletişim kurarak sosyalleştikleri gibi bütün ihtiyaçlarını da iletişim araçlarını kullanarak sağlarlar. Dolayısıyla insanın var olduğu her toplumda birbirlerinden farkl1lıklar gösterse de mutlaka bir iletişim biçimi var olmuştur.

İletişimi simülasyon kuramı ile açıklayan Baudrillard aslında gerçekliğin Batı toplumlarındaki durumunu sorgulamak istiyordu. Ona göre gerçekliğin ortadan kalktı̆̆ı yerde ortaya çıkan simülasyon ilk olarak mesafe kavramını ortadan kaldırmıştı ve onun yerine bir hiper-gerçeklik meydana getirmiştir. Bu hipergerçeklik ise "gerçeklikten yoksun gerçekliğin simülasyonlar" aracılığıyla üretilmesinden ibarettir (Baudrillard, 1998, s.11). Gerçeğin tüm özelliklerine sahip olan simülasyon için en önemli olan şey biçimdir. Bu biçimin içeriği olmadığı gibi bunu da çok önemsemez. Baudrillard bu durumu çağımızın en büyük hastalığı olarak tanımlar yani gerçeğin üretimi ve yeniden üretimi. Gerçeklik ortadan kalmıştır ve yerine göstergeler gelmiştir. Gösterge, bir dil sisteminde iletişimin en küçük birimi olarak düşünülür bir kelime, bir ses, ekrandaki görüntü, müzik notası, hareket, nesne ya da kıyafet olabilir. Gösterge olabilmesi için kendinden başka bir şeyi ifade etmelidir (Turner, 2016, s.28). Baudrillard, başta televizyon olmak üzere her çeşit iletişim aracını her an ve her yerde sonsuz sayıda anlam üreten araçlar olarak tanımlar. 
Ona göre insan, aşırı anlam bolluğu içerisinde büyük bir anlamsızlık içerisinde bocalamaktadır. Dolayısıyla iletişim kanallarını genişlettiğini düşündüğümüz her tür araç, bizi gerçeğe yaklaştırmadığı gibi gerçekten uzaklaştırmaktadır.

Sosyal medya iletişiminde kullanıcılar, duygu ve düşüncelerini, sevinç ve nefretlerini, dünya görüşlerini, umutlarını ve yaşamdan beklentilerini dil ile yazı aracılığıyla gerçekleştirirler. Bu bakımdan hem gerçek yaşamda hem de sosyal medyada kültürün taşıyıcı öznesi birey tarafından kullanılan dildir. Sözün hammaddesi sözcüklerdir. Sözcükler var olanların ne ve kim olduklarını (isimler), nasıl olduklarını (sıfatlar) ve ne yapıp ettiklerini (fiiller) çeşitli soyutlama düzeylerinde ifade eder (Çelebi, 2007:, s.10). Toplumların kendi sosyolojik ve tarihsel gerçeklikleri doğrultusunda geliştirilmiş oldukları özlü sözler, ata sözleri deyimler de dil aracılığıyla kültürün kuşaktan kuşağa aktarılmasını ifade eder. Özellikle sosyal medyayı kullanan gençler hem geçmişten kendilerine tevarüs eden sözleri kendi mecralarında paylaşarak kültürlenmekte hem de yeni olgular doğrultusunda yeni sözler üretmektedirler. Sosyal medya dili yeni bir dildir. Kendi kavramları, kendi kısaltmaları, sembolleri, duyguları ifade etmek için her gün yenileri eklenen yüzlerce emojileri ile gelecek kuşaklar için yeni bir dil inşa etmektedirler.

Sosyal medyada kültürün en önemli belirleyicilerinden birisi olan kimlikte yeniden inşa edilmektedir. Sosyal medya kullanıcıları, kendilerini ait hissettikleri gruplarla dayanışma platformları oluşturmakta, zaman ve mekan kavramina gereksinim duymadan, istedikleri an birbirleri ile iletişim kurabilmektedirler. Sanal topluluklar, sanal cemaatler, sanal ilişkiler, sanal aşklar ve sanal duygular gerçeğin yerini almakta, bireyler sanal dünyaya kendilerini sınırsızca teslim ettikçe sosyalleşmek yerine asosyalleşmektedirler. Modern dünyanın ve kent yaşamının bireyler üzerindeki en olumsuz etkilerinden birisi olan yalnızlık, sanal kalabalıklara rağmen kurdukları kişilerin anlık haberleri sayesinde ölümlerden, dügünlerden, doğum günlerinden, mevlitlerden, günlerden çok hızlı biçimde haberdar olabilmelerine rağmen gerçek dünyada giderek yalnızlaşmaya devam etmektedirler.

Sosyal medya geleneksel kültür kodlarının bazılarını alarak kendi yapısına uygun hale getirmiş bazıları ise sosyal medya kültüründe kendisine yer bulamamıştır. $\mathrm{Bu}$ anlamda toplumsal dayanışmanın ve 
toplumu bir arada tutan en önemli unsurlardan birisi olan geleneğin sosyal medyada ciddi anlamda aşındığını, yıprandığını, yenilenemeyen yanlarının yok olduğunu görmekteyiz. Geçmişten günümüze taşınan gelenek, görenek, töre gibi kavramların yerini yepyeni kavramlar almaktadır. Türkçe'de sürmek anlamından türetilen gelenek, Osmanlı'da ananenin bir yan anlamı olmakla birlikte katı ve yumuşak yaptırımları olan, bir şey yaparken belli yolları izleme imkanı veren, geçmiş zamanlardan beri süregelmekte olan toplumsal ve kültürel davranış kalıplarını ifade etmek için kullanılmaktadır.(Aydın, 2018, s.42) Sosyal medya toplumun doğasında içkin olarak varlığını sürdüren birçok davranış ve düşünce kalıbını yeniden şekillendirmekte ve bu anlamda kendi geleneğini inşa etmektedir. Tam da Turner'ın ifade ettiği gibi "eski kültür gitmişti çünkü onu üreten hayat biçimi yok olmuştu" (Turner, 2016, s.89).

Sosyal süreçler olarak tanımlanan ve toplumsal yapıdaki kültürel bileşenleri oluşturan işbirliği, uyarlanma, özümsenme, çatışma, karşıtlık ve rekabet gibi süreçlerin tamamı sosyal medyada, kendine özgü doğasında, yeniden üretilmekte ve tanımlanmaktadır. Sosyal medya kullanıcıları arasında kimi zaman çatışma ve karşıtlıklar gruplar ve topluluklar üzerinden yürümektedir. Gerçekliği kanıtlanmamış bilgiler, yanlış kurgulanmış haberler, üzerinde çeşitli bilgisayar programları ile oynanarak saptırılan resimler, ses ve efektleri değiştirilmiş çarpık videolar çoğu zaman istenmeyen düşmana karşı üretilmiş sosyal silahlardır. Çoğu ülkede ki yasal boşluklar ve medya etiğinin yeterince oturmamış olduğu topluluklarda böylesine durumlar hiçbir yaptırımla cezalandırılmamaktadır. Bu da yalan haber üreterek bu haberlerin yayılması için özel çaba sarf edenlere, bunlar kimi zaman bir siyasi parti organizasyonu olabildiği gibi kimi zaman da ücretli profesyoneller olabilir, zemin hazırlamaktadır.

Sosyal medyanın görünür işlevleri ve gizli işlevleri de bulunmaktadır. Merton'a göre, görünür işlevler insanların gözlemledikleri ya da bekledikleri sonuçları ifade ederken, ne anlaşılmış olan ne de beklenilen sonuçlar gizli işlevleri ifade etmektedir. (Wallece-Wolf, 2002, s.66) sosyal medya kurucuları bu işi ilk kurdukları zaman yapmış oldukları işin böylesine büyüyeceğini, sınırları ve ülkeleri aşacağını, kültürler ve dinler arası bir genişliğe ulaşacağını hesaplamamışlardı. Sosyal medyayı son derece basit gerekçelerle kurdular. Ancak süreç içerisinde en büyük sıçramayı ilkin ticari kullanımda yaşadılar. Yöneticiler işe alacakları çalışanları bile sosyal 
medyadan incelemeye aldılar (Baert, 2017, s.1223). Ticari alanda yakalanan başarıyı taçlandırmak için hem üreticiler hem de tüketiciler için yeni ara yüzler ortaya çıkardılar. Gelinen süreç tüketiciler için son derece ümit vericiydi. Sosyal medya da ürünlerinin tanıtımlarını yapmak, tüketicilere ulaşmak geleneksel medya araçlarına göre hızlı olduğu kadar ucuzdu da. Bütün bunlarla birlikte doğru hedef kitlesine ulaşabilmelerine imkan tanıyan yazılımlar sayesinde ticari ürünlerini çok daha kolayca pazarlayabildiler. Sanal dünyanın tüccarlara sunduğu en büyük hediye ise ne devletlerin gümrük kotalarına takılmaları ne de devletlerin ithal ürünler için uygulamış oldukları aşırı vergilere takılmak oldu. Günümüzde devletler sanal ticaretin bu boyutunu ciddi anlamda masaya yatırmış olsalar da henüz sürecin nasıl sonuçlanacağı çok açık biçimde ortaya çıkmamış olmakla birlikte gelecek ulus-aşırı küresel şirketlerin galibiyetine işaret etmektedir.

Sosyal medya kullanıcıları arasında yerli kültür, yabancı kültür ve alt kültürler arasında farklı etkileşimler vardır. Birbirinden farklı kültürler arasında sosyal medya da etkileşimler yaşanır. Bu etkileşimler sonucunda yerli kültürler de yabancı kültürlerde alt kültürlerde değişir. Çeşitli kültürlerde ki değişimin niteliği ve değişimin hangi kültürde daha fazla gerçekleştiği egemen kültürle daha yakından ilgilidir. Baskın kültür ve diğer kültürleri daha fazla değiştiren kültür hakim kültürdür. Günümüzde batı kültürü doğu kültürleri üzerinde daha baskındır ve dönüştürücü gücü daha fazladır. Modernleşmekte olan ülkeler toplumsal tercihlerinde batı kültürünün üretmiş olduğu şeyleri daha fazla tüketmeye çalışmaktadırlar. Kendi kültürlerini de bırakmak istemeyen batı dışı toplumlar bu sürecin sonunda geçiş dönemi kültürlerini ifade eden transkültürasyon sürecini yaşamaktadırlar. Batı kültürü sosyal medya aracılı̆̆ıyla modernleşmekte olan ülke gençliğine kimi zaman kültür şoku yaşatmakta kimi zaman ise kendi kültürünü hakim kültür haline getirebilmek için asimilasyona başvurmaktadır. Böylelikle sosyal medyada paylaşılan bilgi yoğunluğu yüzünden sosyal medyada bilgi paylaşımları arttıkça insanlar bilgi yoğunluğundan gerçek ve doğru bilginin ne olduğu konusunda zorlanacaklar ve tercih yapmak zorunda kalacaklar (Mandilberg, 2012, s.74).

Adam Acar, sosyal medyanın kültürel değişimi nasıl başardığını açıklayama çalıştığı eserinde dünya üzerinde binlerce kültür olduğunu ve 
kültürlerinde birbirlerinden oldukça farklı olduğunu bildiğini ancak bu kadar kısa sürede sosyal medyanın neden bu kadar kabul gördüğünü açıklamanın zorlukları olduğunun altını çiziyor. Farklı bir bakış açısına göre sosyal medyanın sosyal değişimi teşvik etme ve kolaylaştırma olanakları sadece kollektif hayallerimizin kisitlamalarıyla sinırlı olmasina rağmen (Al-Deen ve Endricks, 2011, s.85) ona göre çekirdek kültür üzerinde yükselen sosyal medyayı bu kadar güçlendiren üç neden bulunmakta. Bunlardan birincisi sanal iletişim teknolojilerinin neredeyse tamamının kendisini sosyal medya olarak tanımlaması. İkincisi insanların kendi bireyselliklerini burada özgürce paylaşabilmeleri ve üçüncüsü ise sosyal medya kültürünün oluşması olarak gösterir (Acar, 2014, s.158).

Sosyal medyaya yöneltilen bazı eleştirilen başında "gençliği yoldan çıkardığı" iddiası gelmektedir. Badiou, Sokrates'in Yunanlar tarafından gençliği yoldan çıkardığı için ölüme mahkum edildiğini söyler ve "genliği yoldan çıkarmanın" cinsellik, para ve iktidar üçlemesinin bir araya gelmesiyle oluşabilecek bir durum olduğunu ileri sürer. Gene ona göre bu üçleme doğru yoldan sapmanın ve yozlaşmanın en büyük tetikleyicileri olarak algılanmıştır. Sokrates'in iktidarı elde etmek için sözün gücünün ayartıcılığını kullanarak iktidarı ele geçirmek amacı taşıdığını iddia etmektir (Badiou, 2016, s.14). Oysa durum tamamen bunun tersi olup, Platon'un da ifade ettiği gibi iktidarın yozlaştırıcılığına bir meydan okumaydı, onun göstermek istediği tek şey "gerçek yaşam" dı.

\section{Sonuç:}

İletişim teknolojilerinin yaygınlaşmasıyla paralel olarak sosyal medya kullanımı ve sıklığı giderek artmaktadır. Teknolojiye erişimde sosyoekonomik şartlardan dolayı daha zor erişim sağlayabilen ülkelerde dahi sosyal medya kullanımı giderek artmaktadır. Bu anlamda dünya üzerinde kaç sosyal medya kullanıcısının bulunduğunu tespit, sisteme her saniye binlerce kişinin katılması yüzünden tam olarak tespit edilememektedir. Sosyal medya kullanıcıları ile ilgili "şimdi" ve "şu anda" verilen en güncel sayısal veriler bile saatler içerisinde anlamını yitirmekte ve eski hükmüne geçmektedir.

Hem sosyal medya kullanıcıları hem de sosyal medya mecralarının üreticileri sürekli kendilerini yenilemektedir. Tüketicilerin sosyal medya 
mecralarından beklentileri sürekli arttığı gibi sosyal medyadan beklentiler de çeşitlenmektedir.

Sosyal medya kültürler arasında bir etkileşime neden olmaktadır. Hakim söylem ve egemen kültür diğer kültürleri daha fazla etkilemektedir. Batı kültürlerinde değişim modernleşmekte olan ülkelerde ki kültürel değişime nazaran daha az olduğu gözlemlenmektedir. Bunun nedeni ise batı kültürlerinin değişime kapalı olmaları değil, kendi içlerinde kültürel devinimi en yüksek düzeyde zaten gerçekleştirmiş olduklarına olan inanç yatmaktadır. Modernleşmekte olan kültürler ise kendi toplumsal ve ekonomik şartları ile batının şartlarını sürekli karşılaştırmakta ve bu karşılaştırmalar sonucunda kendi konumlarının iyi olmadığı kanaatine ulaşmaktadırlar. Bu anlamda modernleşmekte olan ülkelerde kültürel değişim daha hızlı ve daha fazla alanda olmaktadır. Kültürel değişimin sonuçları ise bambaşka bir çalışmanın konusu olabilecek kadar karmaşıktır.

Gençlik, sosyal medya aracılığıyla bir çok pozitif edinim kazanmaktadır. Her ne kadar sosyal medyanın gençliğe olumsuz etkileri daha fazla gündem konusu ediliyor olsa da sosyal medyanın gençliğe kattı̆̆ pozitif edinimler de gözden kaçırılmamalıdır. Sosyal medya kullanıcısı ve sosyal medyanın üreticisi olarak gençliğin sosyal medya kullanımı konusunda bilinç düzeyi iyileştirilirse bu mecrayı daha verimli kullanacağı açıktır. Bu kapsamda gündelik yaşamda sosyal medyayı kötüleme üzerine kurgulanan dilin yerini daha ölçülü bir dil almaya başladığı takdirde gençliğin sosyal medya kullanımında pozitif yönleri ön plana çıartıcı bir yöntem belirlenebilecektir. Sosyal medyayı "bütün kötülüklerin anası" olarak görmek yerine, onun toplumsal yaşama ve bireysel hayata zararları ve katkılarıyla değerlendirerek daha sağlıklı bir bakış açısıyla hareket edilmelidir.

Bütün bunlarla birlikte sosyal medyanın bilgi güvenliği konusunda son derece kötü bir mecra olduğu da bilinen bir gerçektir. İngiltere merkezli Cambridge Analytica, 'This Is Your Digital Life' adlı uygulama ile 50 milyon kullanıcının kişisel bilgisini ele geçirdiği ve 2016'da yapılan ABD seçimlerinde çıkar amaçlı kullandığı ortaya çıkmıştı. Bireyler kendileri hakkında son derece ayrıntılı bilgileri, gönüllü olarak sosyal medyaya yüklemiş olduklarından dolayı istihbarat güçlerinin elini rahatlatıyorlar. Dolayısıyla kişisel bilgilerin güvenliği sorunu basit ya da 
profesyonel dolandırıcılık gibi adi suçlardan daha büyük sorunlar yaratmaktadır. Son dönemde Facebook'ta kişisel bilgilerin kötü niyetli insanların eline geçtiği ile ilgili basında yer alan ve büyük oranda gerçeği yansitan haberler sonrasında binlerce insan hesaplarını ya kapattılar ya da bir süreliğine dondurdular. Sosyal medya kullanıcılarını en fazla tedirgin eden sorunların başında bilgi güvenliği sorunu gelmektedir. Her ne kadar sosyal medya mecralarını sahiplerin de siber saldırılar karşısında kendi ticari ürünlerinin güvenliğini sağlamak için ciddi çaba gösterdiklerini ifade etseler de, söz konusu ulusal güvenlik gibi meseleler olduğunda da bilgileri cömertçe paylaşmaktan geri durmadıkları da bilinen bir gerçektir. 
EXTENDED ABSTRACT

\title{
The Effect of Social Media as a Means of Re-production of Culture on Young People
}

\author{
Serkan Yorgancilar
}

Gazi University

Some concepts have a very important place in the lives of humans and community. The first method employed for describing any phenomenon in social sciences is its limitation. A concept, which is large enough to include everything, is problematic; and does not fit to the social sciences methodology. One of the most important among these concepts whose limits are not drawn well and which are almost not completed in human and social life and therefore confusing about what it covers and what does not cover is the culture concept. The efforts by Pierre Bourdieu, Alfred Weber, Lipp, who are considered as important theoreticians in culture sociology, may be given as the examples for this. Although it is hypothesized that the culture concept has been in use for 150 years, the first thinker who first defined this concept was Tylor (Aydın, 2018, p.46).

The difficulty of defining and limiting culture has become a situation that is accepted commonly by nearly all social scientists. As a matter of fact, some social scientists believe that the presence of such an unlimited definition for a concept, and the fact that many social scientists have not been able to agree on a concept pose also a serious problem. The unlimited contents of the culture concept cause difficulties in defining it.

In this respect, firstly, we made a preference among culture definitions in the present study of ours, and discussed the reproduction phenomenon of culture. It is hypothesized that culture is reproduced in different ways in today's societies. For the purpose of limiting our study, only the social media were taken as the subject matter among various social structures in which culture is reproduced.

It is already well-known that social media is mostly used by young people, and plays a very important role in the social life of young people. It is considered that social media will cause serious changes in the lives of 
all parts of the society, especially for young people with the increase of technological advances. I believe that it is especially important to understand the relation between social media and young people to understand the speed and direction of cultural change, because social media is the largest cultural change field for young people today.

According to TUIK data, the computer and internet use is becoming more widespread in our country. When computer and internet use is considered together, the usage rates in 16-74 age group were $56.6 \%$ and $66.8 \%$, respectively in 2017 . These rates became $54.9 \%$ and $61.2 \%$, respectively in 2016. The computer and Internet usage rates were $65.7 \%$ and $75.1 \%$ in males in $16-74$ age group; and $47.7 \%$ and $58.7 \%$ in females. Men have more access to computers and internet than women in our country. Thanks to the facilitation and access to technology, internet use has increased considerably. Again, according to TUIK data, people in Turkey can provide access to internet in their homes at an extremely high rate with $80.7 \%$ (TUIK, 2018)

An extensive study was conducted by the British Council in 12 cities in 2017, which included 2524 young people who were between the ages of 18 and 30, on social media use and on some other issues. A total of $97 \%$ of the participants stated that they used WhatsApp and other social media applications regularly on a daily basis. Previous quantitative studies on social media become outdated in a short time as people use social media in more active and different ways. For example, when we compare today's data with previous data, in a study conducted in the UK in July 2007, we see that the frequency of using social networks was measured as only once a week (Livingstone, 2016, p. 91), which shows that the digital data change in a very fast way. The British Council conducted a study on young Turks in Turkey and reported that Turkish young people used social media over two hours per day, and of course, for now (British Council, 2017, p.16). The use of social media in these rates in daily life should be put on the table by social scientists, and comments should be made on the reasons of this. In this context, the cultural change and the effect of social media on this have been discussed by making use of the official statistics and scientific studies on Turkish youth. 
Firstly, a literature review was carried out on the reproduction of culture; and scientific studies on this subject were reviewed. Then, the scope of this review was narrowed down in the field of culture and reproduction, and the study was expanded in line with the viewpoints of Pierre Bourdieu.

Secondly, the frequency of social media use by young people was determined according to the effects of social media and official and scientific statistics that were released under the headings of social media and young people.

\section{Findings and Discussion}

Parallel to the spread of communication technologies, social media use and frequency is increasing with each passing day. The use of social media is increasing even in countries where access to technology is more difficult because of socio-economic conditions. In this respect, it is not possible to determine the number of social media users on the world as thousands of people join the system with each passing second. Even the most up-todate digital data on social media users provided "now" and "right now" are lost in hours, and researchers go back to former conclusions.

Both social media users and producers of the channels of it are renewing themselves in a constant manner. The expectations of consumers from social media are increasing and becoming diversified in a constant manner.

Social media causes interactions among cultures. The dominant discourse and the culture affect other cultures more. It was observed that the change in Western cultures is less compared to that of the modernizing countries. The reason for this is not that the western cultures are closed to change, but the belief that the cultural activity within themselves is already fulfilled. Modernizing cultures, on the other hand, compare their social and economic conditions continuously with the conditions in the Western countries, and come to a conclusion that their position is not good. In this sense, cultural change occurs faster and more in modernizing countries. The outcomes of cultural change are adequately complex to be the subject of another study. 
Young people acquire many positive gains via social media. Although the negative effects of social media on youth are considered more on the agenda, the positive acquisitions of social media by young people should not be underestimated. If the awareness of using social media in young people is improved as social media users and as producers of it, it is obvious that they will use social media more efficiently. In this context, if the language that is fictionalized on pitying social media in daily life is replaced by a more considerable language, a positive method that will bring positive aspects of using social media may be determined. Instead of considering social media as "the mother of all evil", people should act in a healthier and more accurate manner, and evaluate it with its damages and contributions to social and individual life.

\section{Kaynakça/References}

Acar, A. (2014). Culture and social media: An elementary textbook. Cambridge scholars publishing.

Al-Deen, N. ve Hendricks, J. A. (2011). Social media: Usage and impact. Lexington books.

Alver, K. (2010). Emile Durkheim ve kültür sosyolojisi. Sosyoloji Dergisi, 3(21), 199-210.

Aydın, M. (2018). Kültür sosyolojisinin temel kavramları. Kültür sosyolojisi. Ed: Köksal Alver- Necmettin Doğan. Konya: Çizgi yayınları.

Badiou, A. (2016). Gerçek yaşam: Gençliği yoldan çıkarmaya yönelik bir çağrı. (çev: i. ergüden) İstanbul: Red Kitaplığı Sel Yayıncılık,

Baudrillard J. (1998). Simülakrlar ve simülasyon. Çeviren: Oğuz Adanır. İzmir: Dokuz Eylül Yayınları.

Baert, S. (2017). Facebook profile picture appearance affects recruiters first hiring decisions. New Media \& Society, 20(3), 1220-1239.

Çelebi, N. (2007). Sosyoloji notları. Ankara: Anı Yayıncilık.

Dijk, J. (2016). Senin gibi kullanıcılar mı? kullanıcı türevli içerikteki failliği kurumsallaştırmak (Çev: Bahar Ayaz). Yeni medya kullanıcının yükselişi. Ankara: Ütopya Yayınevi. 
Eliot, T.S. (1987). Kültür üzerine düşünceler. Çev: Sevim Kantarcığlu. Ankara: Kültür Bakanlığg Yayınları.

Giddens, A. (2000). Sosyoloji. Ankara: Ayraç Yayınevi.

Güvenç, B. (2016). Insan ve kültür. İstanbul: Remzi Kitabevi.

Gökalp, Z. (2014). Türkçülüğün esasları. İstanbul: Ötüken Yayınları.

Karataş. Ş. ve Binark. M. (2016). Yeni medyada yaratıcı kültür troller ve ürünleri caps'ler. TRT Akademi, 1(2), 428-448.

Kroeber, A.L. ve Kluckhohn. C. (1952). Culture-critical review of concepts and definations. Usa: Cambridge-massachusetts published by the museum.

Livingstone, S. (2007). Gençliğe ilişkin içerik oluşturmada riskli fırsatları değerlendirmek. (çev: ayşe yıldız) Yeni Medya Kullanıcının Yükselişi. Ankara: Ütopya Yayınları.

Macmillian (2002). English dictionary for advanced learners. London: Bloomsbury Publishing. london.

Marshall, G. (1992). Sosyoloji sözlüğ̈̈. İstanbul: Bilim Ve Sanat Yayınları. istanbul

Mandiberg, M. (2012). The social media reader. Nyu Press

Simmel, G. (2009). Bireysellik ve kültür. çev: Tuncay Birkan. İstanbul: Metis Yayınları.

Smith. P-Riley A. (2016) Kültürel kurama giriş. (Çev: Selime Güzelsarı-Ibrahim Gündoğdu) Ankara: Dipnot Yayınları.

Turner, G. (2016). Ingiliz kültürel çalışmaları (Çev: D. Özçetin \& B. Özçetin) Ankara: Heretik Yayınları.

Türkdoğan, O. (2015). Ziya Gökalp ve sosyolojik düşünme sistemi. Konya: Çizgi Kitabevi.

Wallece. R. ve Wolf. A. (2002). Çağdaş sosyoloji kuramları. Çev: Rami AyasLeyla Elburuz, Izmir

Williams, R.(1993). Kültür. Çev: suavi aydın. Ankara: Imge Kitabevi. https://www.yenisafak.com/hayat/sosyal-medya-bize-ne-soyler-3176964 (20.08.2018)

http://www.tdk.gov.tr/index.php?option=com_gts\&arama=gts\&guid=tdk.gts.5ad3a2267ac9e6.20108192 (15.04.2018) 


\section{Kaynakça Bilgisi / Citation Information}

Yorgancılar, S. (2018). Kültürün yeniden üretim aracı olarak sosyal medya'nin gençliğe etkisi. OPUS-Uluslararası Toplum Araştırmaları Dergisi, 9(16), 2511-2532. DOI: 10.26466/opus.480444 